\title{
Avaliação do Potencial Risco de Contaminação das Águas Subterrâneas na Zona Norte de Natal, RN
}

Evaluation of the Potential Contamination Risk of Groundwater in the North Zone of Natal, RN

Submissão: $25 /$ Set $/ 2018$

Revisão: 10/Dez/2018 Aceite: 30/Dez/2018

\section{Mickaelon Belchior Vasconcelos}

José Geraldo de Melo

José Geilson Alves Demetrio

\section{Rafaela da Silva Alves}

\section{RESUMO}

O suprimento hídrico da zona norte da cidade de Natal é feito por um sistema misto de águas superficiais (Lagoa de Extremoz) e águas subterrâneas. As atividades urbanas vêm se desenvolvendo com taxas elevadas, tendo sido verificado que, em três décadas (entre o ano de 1978 e 2006) a área urbanizada passou de $43,3 \%$ para $78,6 \%$ dos seus $70 \mathrm{~km}^{2}$ de área. Neste trabalho foi feito a caracterização do uso e ocupação do solo, com identificação das fontes potenciais de contaminaçáo e em seguida avaliada a vulnerabilidade natural das águas subterrâneas serem afetadas pelas atividades contaminantes, com a aplicação do método GOD e finalmente, foram definidas as áreas com risco potencial de contaminação do Sistema Aquífero Dunas/Barreiras. Foi verificado que $46 \%$ da área de estudo possui uma vulnerabilidade média quanto a contaminação das águas subterrâneas. Os setores menos vulneráveis são da ordem de $21,6 \%$ e os mais vulneráveis compreendem apenas $9,26 \%$ da superfície total da área. Foram mapeadas e caracterizadas as fontes potenciais de contaminação e em seguida, avaliados os riscos potenciais. A metodologia aplicada na identificação dos riscos em potencial contribuiu com o conhecimento dos impactos do desenvolvimento urbano na área objeto do estudo, tornando factível o desenvolvimento de estratégias de manejo visando a proteção das águas subterrâneas.

Palavras chave: Sistema Aquífero Dunas/Barreiras; Hidrogeologia urbana; Vulnerabilidade do aquífero; Potencial de risco

\section{ABSTRACT}

The water supply of the northern zone of the city of Natal is made by a mixed system of superficial waters (Extremoz Lagoon) and groundwater. Urban activities have been developing at high rates, and in three decades (between 1978 and 20016) the urbanized area increased from $43.3 \%$ to $78.6 \%$ of its $70 \mathrm{~km}^{2}$ area. In this work the characterization of soil use and occupation was carried out, with identification of the potential sources of contamination and then the natural vulnerability of the groundwater to be affected by the contaminating activities, with the application of the GOD method and finally the areas with potential risk of contamination of the Dunas/Barreiras Aquifer System. It was verified that $46 \%$ of the study area has a medium vulnerability to contamination of groundwater. The most vulnerable sectors are of the order of $21.6 \%$ and the most vulnerable comprise only $9.26 \%$ of the total area of $70 \mathrm{~km}^{2}$. Potential sources of contamination were mapped and characterized and then potential risks were assessed. The methodology applied in the identification of potential risks contributed to the knowledge of the impacts of urban development in the area of study, making feasible the development of management strategies aiming at the protection of groundwater.

Keywords: Dunas/Barreiras aquifer system; Urban hydrogeology; Aquifer vulnerability; Potential pollution risk. 


\section{INTRODUÇÁO}

O aumento populacional induz a necessidade de diversas estruturas básicas, como: abastecimento de água, saneamento, drenagem, iluminação, saúde dentre outros. Muitas vezes ocorre que as estruturas básicas não são instaladas em tempo hábil de tal forma anteceder o processo de instalação das populaçóes. A falta de saneamento em áreas urbanas gera na maioria das vezes problemas relacionados com a contaminação das águas subterrâneas. Esses problemas ocorrem em muitos núcleos populacionais no Brasil. O resultado desses processos são os impactos ambientais e consequentemente sociais decorrentes da redução da qualidade de vida em relação à degradação gerada ao meio ambiente e, em especial, as águas subterrâneas.

Um dos fatores relevantes que devem ser considerados no processo de urbanização, trata-se da redução da recarga natural dos aquíferos em decorrência da impermeabilização do terreno, modificando assim a dinâmica natural, pois diminui as áreas favoráveis para infiltração natural das águas.
A área de desenvolvimento deste estudo foi à zona norte de Natal, abrangendo parte do município de São Gonçalo do Amarante, totalizando uma área de $70 \mathrm{~km}^{2}$ (Figura 1). O abastecimento da zona norte da cidade de Natal é feito por um sistema misto que integra águas superficiais (Lagoa de Extremoz) e águas subterrâneas (poços tubulares).

O uso das águas da Lagoa de Extremoz praticamente atingiu os limites de suas potencialidades, o que tem resultado em uma maior procura por águas subterrâneas (MELO et al., 2009).

A zona norte da cidade de Natal (Figura 1) foi objeto de estudos hidrogeológicos (COSTA, 1970; MELO et al., 2009, 2010; MELO, 1998, MELO et al. 2012; FUNCERN, 2006a, b; ARAÚJO, 2002; AGÊNCIA NACIONAL DE ÁGUAS, 2012), sendo evidenciado em alguns trabalhos, processos de contaminação das águas subterrâneas por nitrato em consequência da disposição local de efluentes domésticos (fossas e sumidouros).

Neste trabalho foi realizada uma avaliação do uso e da ocupação do solo, identificando as fontes potenciais de contaminação, determinação da vulnerabilidade das

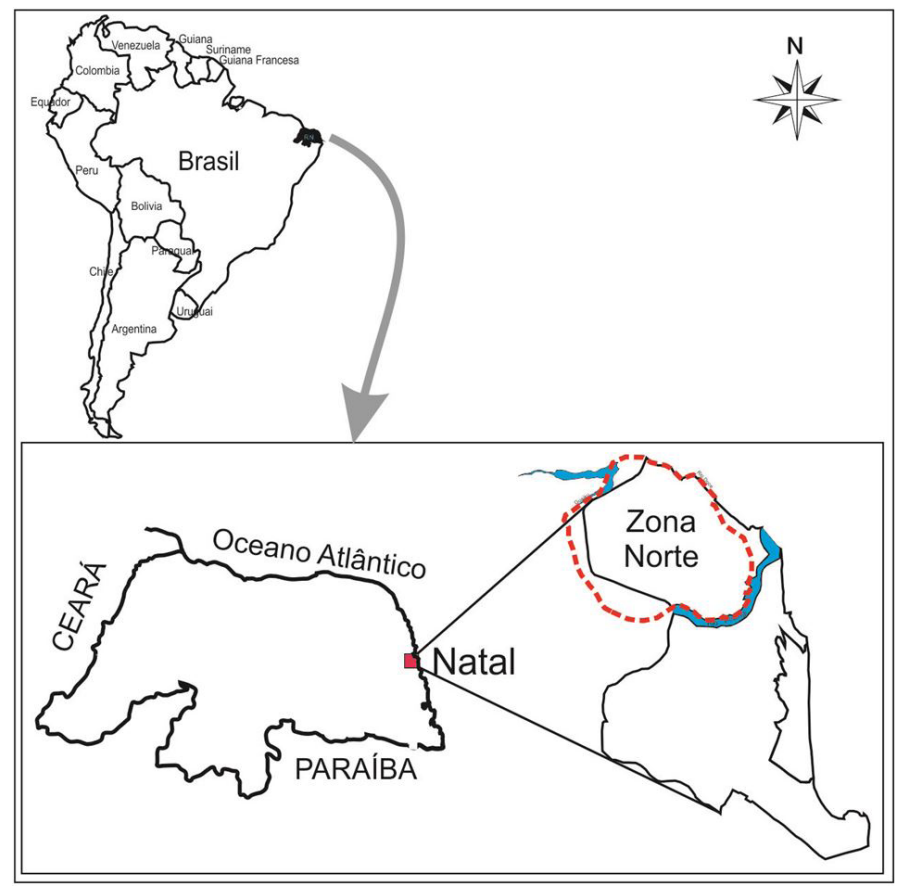

Figura 1 - Localização da área de estudo. 
águas subterrâneas a contaminação e, a definição do risco potencial de contaminação do Sistema Aquífero Dunas/Barreiras. As condições ambientais da área de estudo foram analisadas segundo aspectos históricos de uso e ocupaçáo do solo e condicionamento dos elementos que possam gerar danos à qualidade dos recursos hídricos. A integração dos dados é uma forma de considerar, em uma mesma análise, fatores como os aspectos ambientais de evolução da ocupação do solo, fontes potenciais de contaminação, informaçóes de parâmetros físicos dos aquíferos, vulnerabilidade e risco de contaminação das águas subterrâneas. A partir da integração pretende-se subsidiar informaçóes para o planejamento e gestáo das águas subterrâneas.

\section{ASPECTOS METODOLÓGICOS}

Os procedimentos metodológicos abordados no desenvolvimento tiveram como base o trabalho desenvolvido por Vasconcelos (2010) sendo discutidos os aspectos metodológicos específicos no decorrer das apresentaçóes dos itens a seguir:

a) Evolução no processo de urbanização;

b) Vulnerabilidade das Águas Subterrâneas aos processos de contaminação e;

c) Integração dos dados para determinação do risco potencial de contaminação das águas subterrâneas.

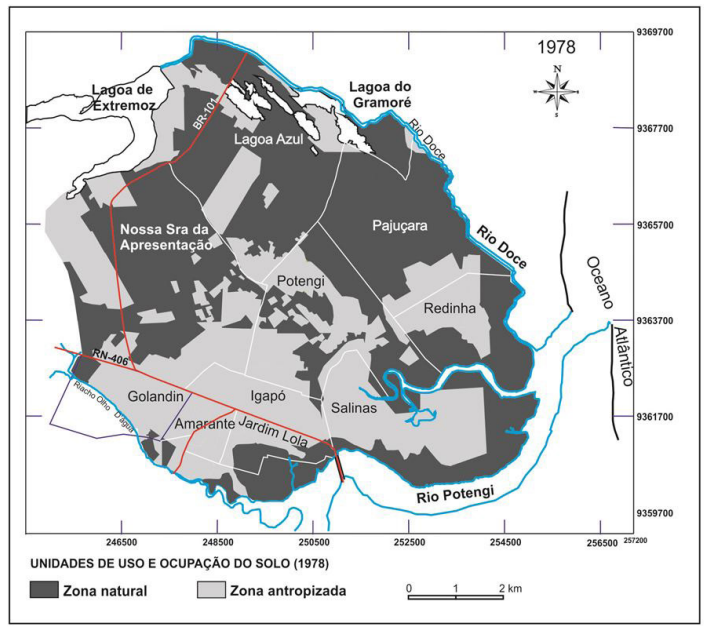

\section{RESULTADOS}

\subsection{Evoluçáo no processo de urbanização}

A urbanização da zona norte de Natal ocorreu de forma bastante acelerada entre a década dos anos de 1970 e 2006 (Figura 2). A instalação de indústrias no domínio da área foi um dos prováveis responsáveis por esse crescimento (VASCONCELOS, 2010). A população entre o ano de 1970 e 2006, aumentou em cerca de cinco vezes e a área urbana expandiu de $11 \%$ para $71 \%$ na Zona Norte (Figura 2). O aumento da ocupaçáo urbana tem gerado problemas no abastecimento: insuficiência de água, problemas de drenagem e contaminação das águas subterrâneas Melo et al. (2012); Melo e Rebouças (1996); Melo e Figueredo (1990). Neste caso, em decorrência da disposição local de efluentes domésticos com o uso de fossas e sumidouros.

A análise dos componentes que interferem nas águas subterrâneas torna-se mais abrangente quando associa-se o estudo do uso e ocupação do solo, assim como fez Migliorini (2000) em Cuiabá-MT.

A elaboração do mapa de ocupação do solo na zona norte de Natal foi desenvolvido com base em fotografias aéreas do ano de 1978 e imagens de satélite do ano de 2006 (Figura 2), sendo apresentadas duas unidades cartográficas básicas (VASCONCELOS, 2010):

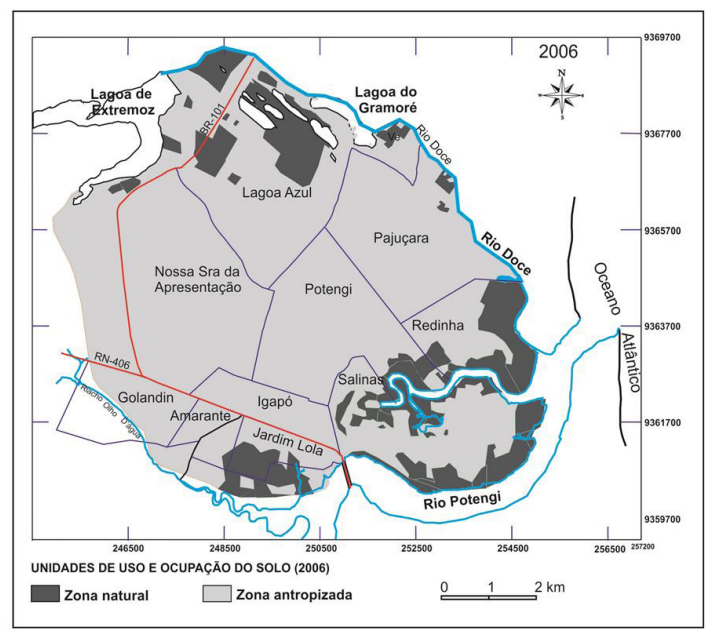

Figura 2 - Mapa da evolução da ocupação do solo na zona norte da cidade de Natal - RN, agrupados em: a) zona natural; b) zona antropizada. Fonte: Melo et al. (2011), com modificaçôes. 
- Zona natural: representada pelas áreas que, aparentemente, através da análise das imagens não sofreram nenhuma interferência humana.

- Zona antropizada: estão inseridas as áreas que sofreram ou sofrem interferência humana.

A partir da análise dos mapas, verifica-se que no ano de 1978 , a zona natural representava 56,7\%, sendo 43,3\% de zona antropizada. Em 2006, a zona antropizada passou a representar $78,6 \%$ e a zona natural $21,4 \%$, ou seja, a área modificou suas características naturais para uma zona com características antrópicas.

Com essa evoluçáo da expansão urbana, podem estar associados diversos fatores que interferem diretamente no ciclo hidrológico, como: a) impermeabilização da área; b) a emissão de efluentes domésticos diretamente nas águas subterrâneas, e; c) construção de poços para captação de águas subterrâneas.

A recarga das águas subterrâneas na área de estudo está garantida, desde que as condiçóes não sejam alteradas significativamente, como a implementação de sistemas eficientes de coleta de esgoto e redução das perdas de águas no sistema de distribuição de águas. Righetto e Rocha (2005) estudando a sustentabilidade do aquífero Dunas/Barreiras possui uma conclusão similar.

\subsection{Vulnerabilidade das Águas Subterrâneas aos Processos Contaminantes}

O termo vulnerabilidade à contaminação do aquífero é utilizado para representar as características intrínsecas que determinam a susceptibilidade de um aquífero de ser adversamente afetado por uma carga contaminante (Foster, 1987).

A vulnerabilidade das águas subterrâneas pode ser definida como a probabilidade de certa proporção de um poluente poder alcançar o aquífero em um determinado tempo (VOIGT et al., 2003). Vrba e Zaporozec (1994) foram os primeiros a distinguir vulnerabilidade em dois tipos: i) vulnerabilidade intrínseca e ii) vulnerabilidade específica.

i) Vulnerabilidade intrínseca: faz uma caracterização relativa, não mensurável, com propriedade adimensional das coberturas das águas subterrâneas, determinada pelas espessuras do material geológico (zona insaturada) e propriedades de recarga do aquífero. $\mathrm{O}$ termo "vulnerabilidade intrínseca à contaminação da água subterrânea” leva em consideração as características geológicas, hidrológicas e hidrogeológicas da área, independente $\mathrm{da}$ natureza do contaminante e do cenário da contaminação Vrba e Zaporozec (1994).

ii) Vulnerabilidade especifica: leva em consideração as propriedades particulares do contaminante ou grupo de contaminante como um complemento da vulnerabilidade intrínseca da área. A vulnerabilidade está condicionada ao risco de exposiçấo da carga contaminante. Os atributos considerados são: uso do solo e densidade populacional (VRBA, 2004), considerando parâmetros naturais, como solo e rocha.

Dentre as diversas metodologias utilizadas para determinar a vulnerabilidade natural das águas subterrâneas, as mais utilizadas na América do Sul são:

- DRASTIC (Depth to water, Recharge, Aquifer media, Soil media, Topography, Impact of vadose zone, Condutivity of the aquifer);

- AVI (Aquifer Vulnerability Index);

- GOD (Groundwater occurrence, Overall lithology of the unsaturated zone, Depth to the water table).

Neste trabalho são apresentadas as determinaçóes da vulnerabilidade à contaminação das águas subterrâneas utilizando o método GOD, pois foi o que melhor se adequou às condiçóes e disponibilidades de dados da área em estudo.

A metodologia GOD foi desenvolvida por Foster e Hirata (1988), sendo considerados três parâmetros (condição hidráulica do aquífero, litologia da zona insaturada e profundidade do aquífero). Por necessitar de apenas três parâmetros para a obtenção do índice de vulnerabilidade, este método torna-se mais acessível, posteriormente, modificado por Foster et al. (2002) na versão em espanhol Foster et al. (2006) na versão em português, sendo amplamente utilizado em diversos trabalhos por exemplo Rauber et al. (2015) e Garcia, Conceição e Peixoto (2018). 


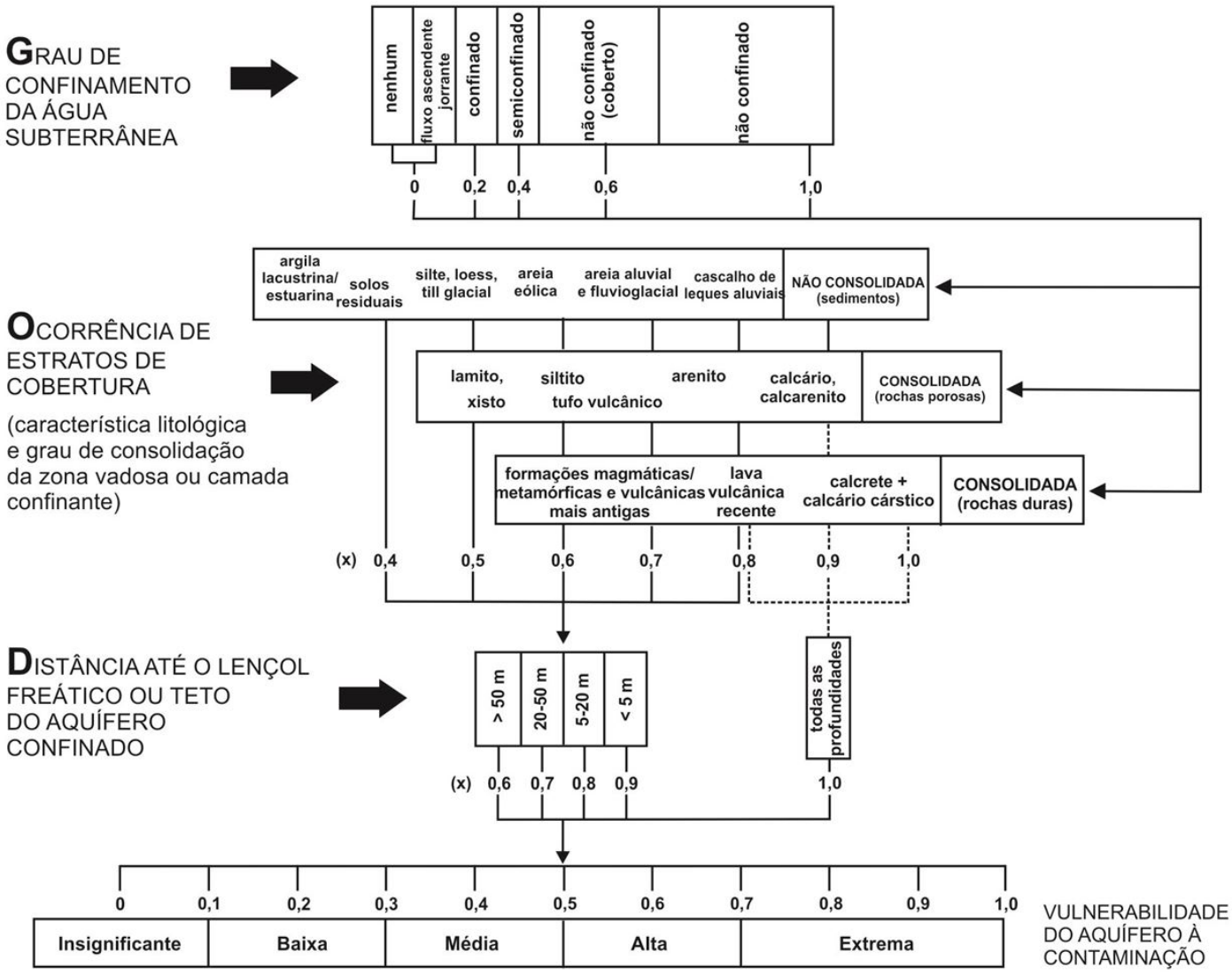

Figura 3 - Diagrama para classificação da vulnerabilidade das águas subterrâneas. Fonte: Foster et al. (2006).

Para cada parâmetro, é atribuído um valor que irá ser gerado um índice paramétrico, o resultado da vulnerabilidade será o produto dos três índices calculados anteriormente no ponto (poço) considerado. A figura 3 apresenta o diagrama esquemático para determinação dos índices de cada parâmetro considerado.

A vulnerabilidade à contaminação das águas subterrâneas na zona norte de Natal foi avaliada com base em informaçóes de profundidade dos níveis d'água (Figura 4) e perfis litológicos de 33 poços tubulares.

As águas subterrâneas afloram nas margens dos rios Potengi e Doce, podendo também possuírem profundidades de até 39,0 m nas zonas com o relevo relativamente mais elevado, como no bairro de Pajuçara e, 31,0 m no bairro Golandin (Sudoeste da área de estudo).
As zonas de mangues e salinas (sul da área de estudo), não foram consideradas na elaboração do mapa de vulnerabilidade, por se tratar de uma zona de descarga de água subterrânea sob influência direta e diária da ação das variaçóes da maré oceânica.

$\mathrm{O}$ condicionamento geológico da área de estudo foi elaborado com base no trabalho de Vasconcelos, Melo e Demétrio (2015) que utilizou a interpretação de imagens de satélite, análise de trabalhos anteriores e, também, a integração de dados de perfis litológicos fornecidos por empresas de perfuraçáo e a Companhia de Abastecimento Público (CAERN). Com isso obteve-se uma visão geral da estrutura geológica da área de estudo, no qual foram identificados áreas com maiores ocorrências de níveis argilosos em subsuperfície (Figura 5). 


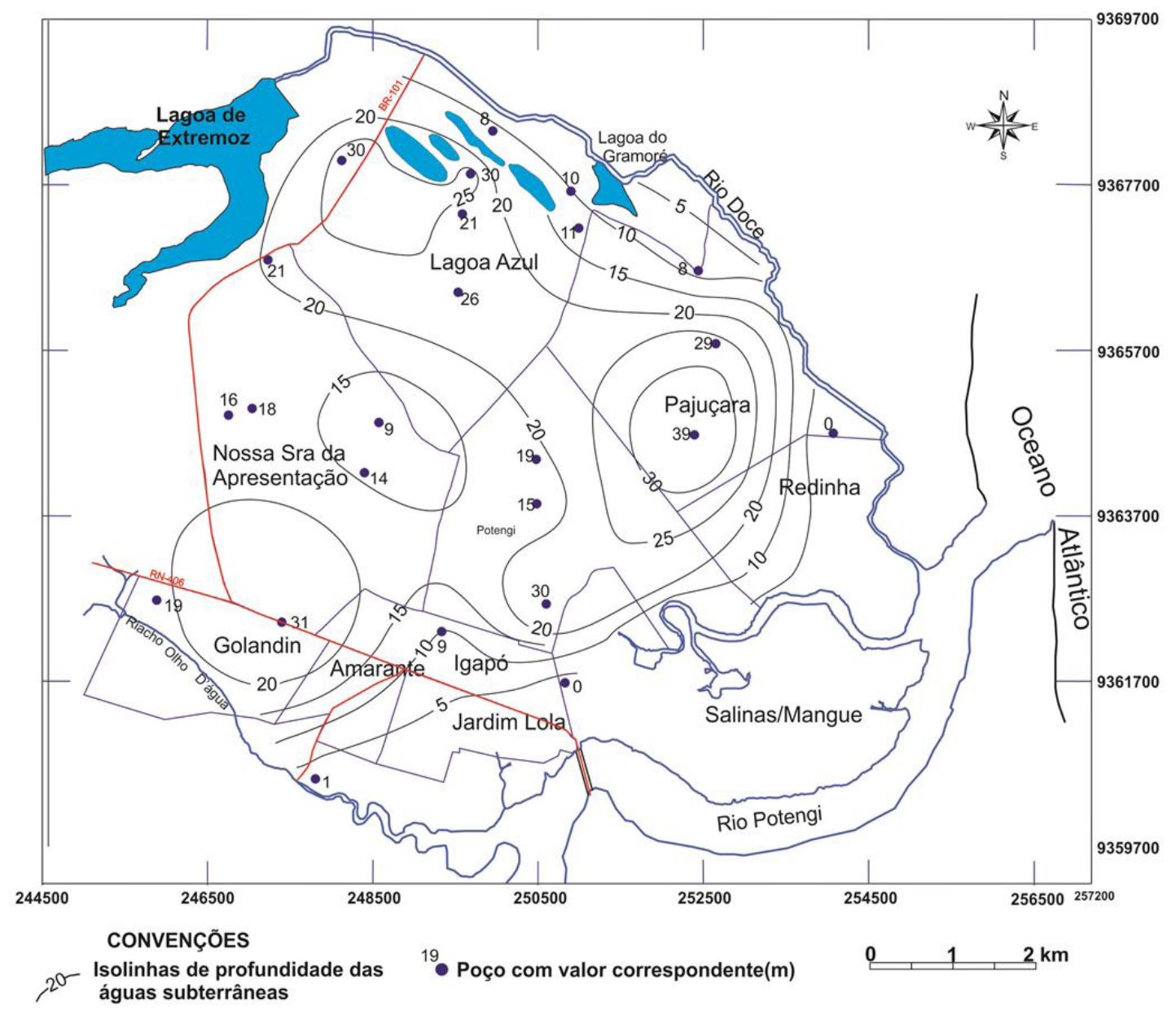

Figura 4 - Profundidade do nível das águas subterrâneas (abril 2008).

A partir do mesmo, verifica-se que existe uma predominância de uma cobertura arenosa do Grupo Barreiras do tipo arenito com intercalaçóes de argila.

Baseado nas informações de condicionamento hidráulico das águas subterrâneas, profundidade da zona saturada e unidades geológicas presentes foi possível gerar o mapa de vulnerabilidade natural das águas subterrâneas à contaminação, apresentado na Figura 6 .

Os setores de baixa vulnerabilidade representam aproximadamente $21,6 \%$ da área de estudo, os quais correspondem aos domínios topograficamente mais elevados. As áreas com vulnerabilidade média apresentam uma maior representatividade espacial no seu conjunto, abrangendo $46,1 \%$ de todo o contexto da área de estudo. As áreas com alta vulnerabilidade estão situadas nas proximidades dos corpos d'água superficiais, ocupando aproximadamente $9,2 \%$, e as zonas com vulnerabilidade extrema representam os locais com ressurgências de águas subterrâneas que abrangem $12,5 \%$ da área de estudo.

\subsection{Avaliação do Risco à Contaminação das Águas Subterrâneas}

A palavra risco denota, em termos gerais, a possibilidade de determinado elemento considerado, humano ou não, em sofrer danos. Castro, Peixoto e Rio (2005) considera que o risco natural está relacionado aos processos e eventos de origem natural ou induzida 


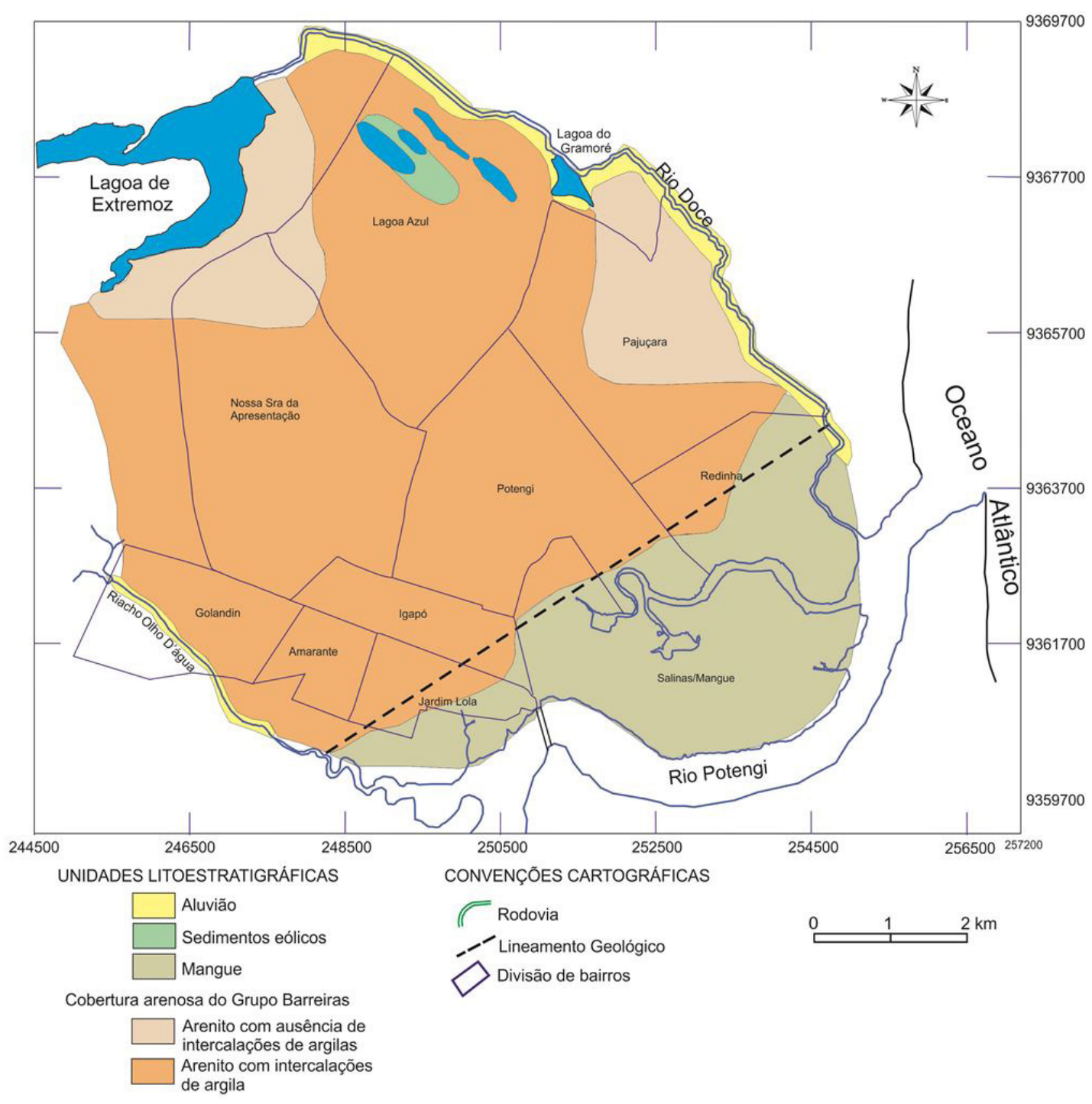

Figura 5 - Unidades litoestratigráficas da zona norte da cidade de Natal-RN.

por atividades humanas, sendo também a categoria de risco social e risco tecnológico.

O risco de contaminação das águas subterrâneas foi avaliado utilizando a metodologia proposta por Foster e Hirata (1993) que considera a interação entre a vulnerabilidade dos aquíferos e a carga contaminante. Nessa condição, foi utilizado o mapa de vulnerabilidade à contaminação das águas subterrâneas, desenvolvido a partir do método GOD e o mapa de fontes potenciais de contaminação (Figura 8).
As fontes potenciais de contaminação foram ponderadas de acordo com o seu potencial de gerar mudanças na qualidade das águas subterrâneas e acarretar prejuízos à saúde humana, sendo classificadas em quatro níveis, segundo as suas potencialidades de contaminação (Tabela 1).

O método abordado possui certa limitação, assim como relatado por Lopes e Scheibe (2015) em que os dados seriam mais significantes se fosse considerada cada carga contaminante. Porém, busca-se generalizar 


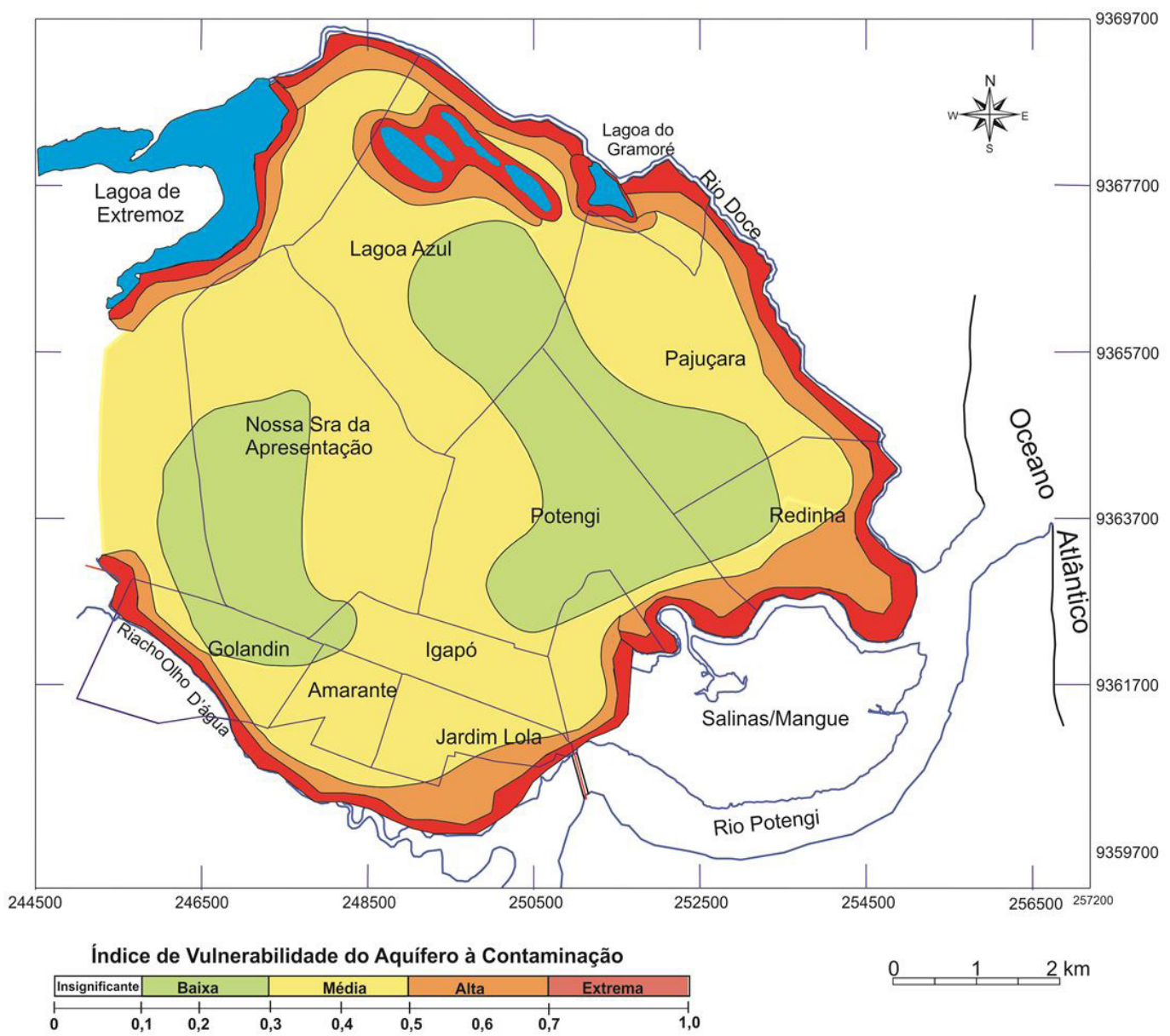

Figura 6 - Vulnerabilidade natural das águas subterrâneas à contaminação, de acordo com o método GOD (FOSTER et al., 2002). Fonte: Vasconcelos (2010).

Tabela 1 - Classes das fontes potenciais de contaminaçấo existentes na zona norte de Natal segundo o potencial de contaminação.

\begin{tabular}{ll}
\hline \multicolumn{1}{c}{ Classe } & \multicolumn{1}{c}{ Características } \\
\hline Baixa & $\begin{array}{l}\text { Reduzida atuação, ou que geram carga de contaminantes, somente quando ocorrem falhas ou } \\
\text { adensamento das fontes. Foram inseridos, nesta classe, a zona industrial e os pontos de lavagem de } \\
\text { veículos e zona urbana. }\end{array}$ \\
Moderada & $\begin{array}{l}\text { Menor carga de efluentes, ou que dependem da lixiviação para percolaçáo até as águas subterrâneas. } \\
\text { Estão inseridas nesta categoria as áreas com rebanho confinado e cemitérios. }\end{array}$ \\
Alta & $\begin{array}{l}\text { Facilidade relativa de ocorrência de vazamentos ou gerar efluentes capazes de alcançar o aquífero, } \\
\text { geralmente, quando possuírem falhas em sua estrutura. Estão inseridas nesta categoria, zonas agrícolas, } \\
\text { lixóes, postos de combustíveis e lagoas de tratamento de efluentes. } \\
\text { Extrema }\end{array}$ \\
& $\begin{array}{l}\text { Proximidade em relação à zona saturada e/ou possui uma ação direta nas águas subterrâneas. Estão } \\
\text { inseridas nesta classe as lagoas de infiltração e poços abandonados. }\end{array}$ \\
\hline
\end{tabular}




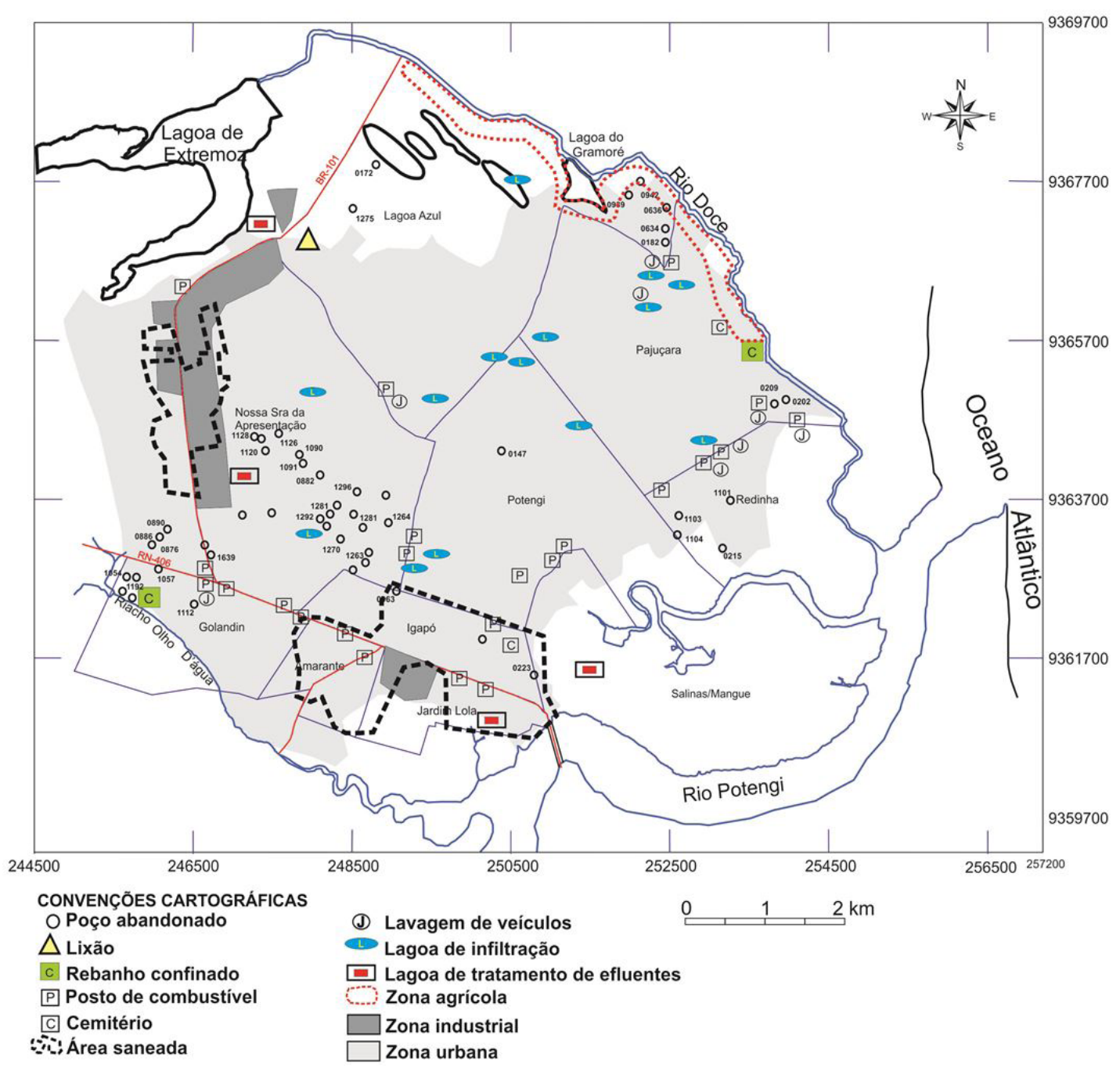

Figura 7 - Fontes potenciais de contaminação da zona norte de Natal no ano de 2008. Fonte: Vasconcelos (2010).

e traçar um perfil aproximado da situação instalada na área de estudo.

No mapa de fontes potenciais de contaminação apresentado na figura 7 são identificados o tipo de estrutura instalada que posteriormente será correlacionada com a vulnerabilidade do aquífero a contaminação.

O potencial de risco foi calculado a partir de um diagrama (Figura 9) que relaciona a classificação da vulnerabilidade (baixa, média, alta e extrema) com o potencial da carga contaminante (baixo, moderado, alto e extremo). A partir da interação destes parâmetros, o potencial de risco das águas subterrâneas, é classificado como: baixo, moderado ou forte.

$\mathrm{Na}$ elaboração do mapa de potencial de risco de contaminação das águas subterrâneas, foi gerada uma malha que se adequasse à escala de apresentação, sendo adotados quadrantes de $500 \mathrm{~m}$ de largura por $500 \mathrm{~m}$ de comprimento (Figura 8). A partir desta malha, foram generalizadas as informaçóes que continham em cada quadrante (vulnerabilidade e potencialidade 


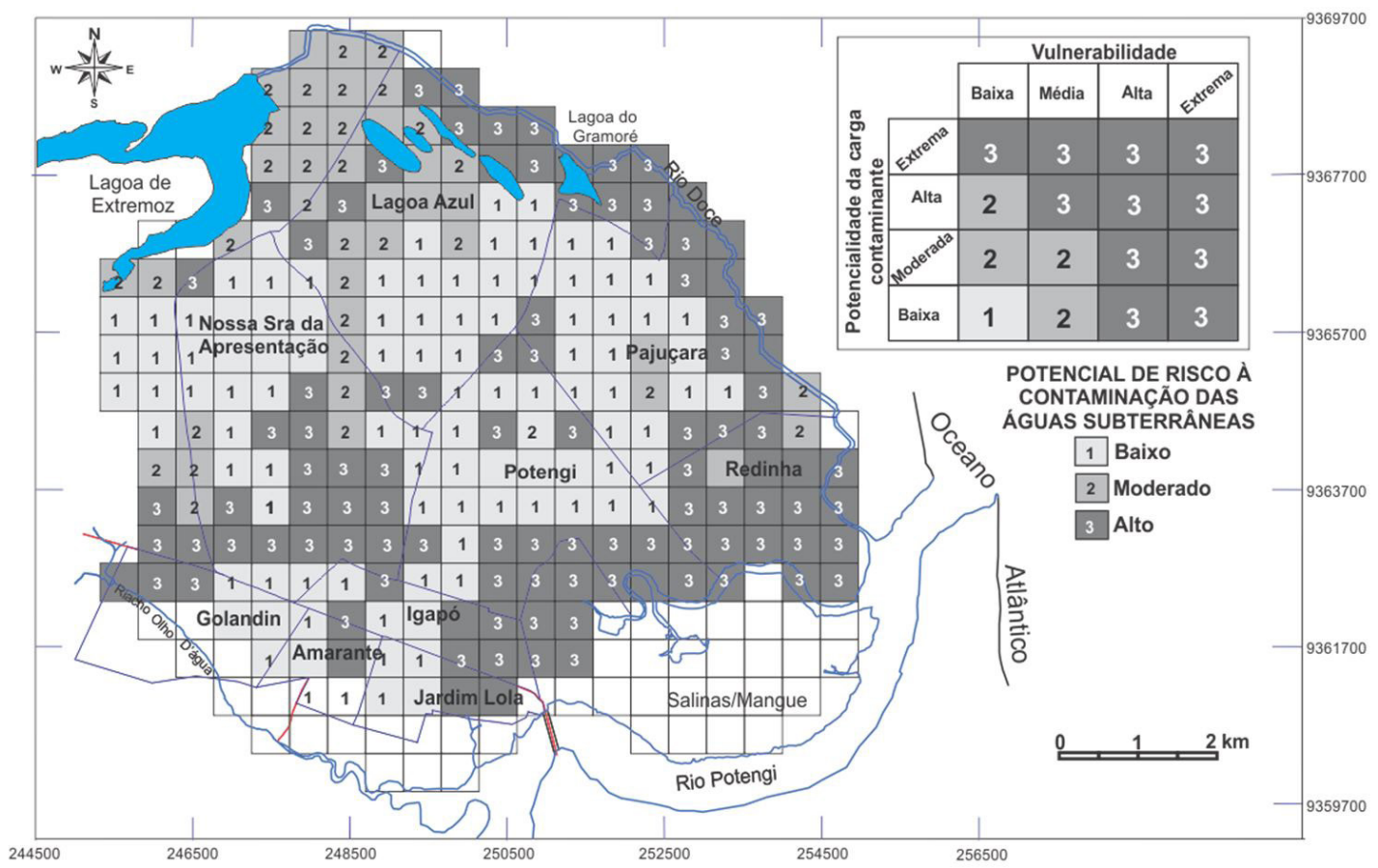

Figura 8 - Potencial de risco à contaminação das águas subterrâneas na zona norte de Natal para o ano de 2008. Fonte: Vasconcelos (2010).

da carga contaminante) e determinou-se o potencial de risco para cada delimitação.

A configuração do mapa mostra que ocorre uma predominância de risco moderado na parte central da área, com as zonas de risco forte localizadas às margens do rio Doce e parte do bairro de Nossa Senhora da Apresentação. O potencial de baixo risco ocorre de forma isolada nos bairros da Redinha e Pajuçara, em decorrência, principalmente, da elevada profundidade do nível das águas subterrâneas.

As lagoas de infiltraçóes, construídas para facilitar a drenagem das águas superficiais, em alguns casos, são utilizadas como locais para despejo de esgotos domésticos. A destinação de esgotos domésticos, nestas lagoas, contribui com a proliferação de insetos e possível contaminação direta das águas subterrâneas.

Diante das atividades desenvolvidas nesse trabalho, o processo metodológico executado para o mesmo é apresentado de forma esquemática na figura 9 . Na mesma pode se verificar os processos básicos executados:

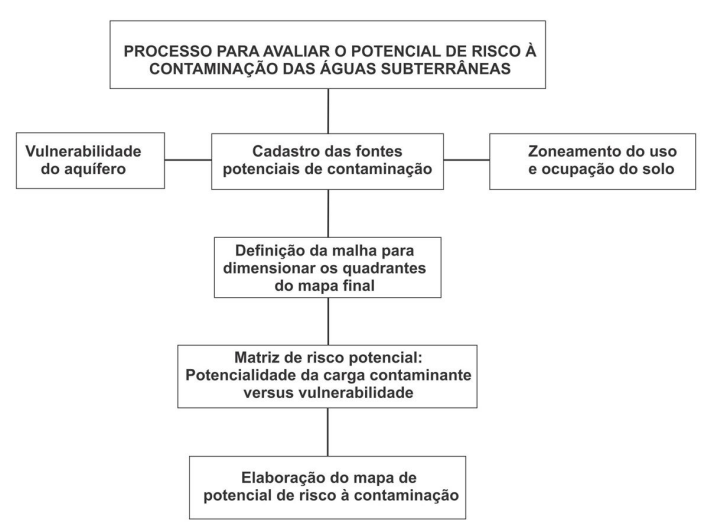

Figura 9 - Diagrama esquemático com as etapas envolvidas para determinação do potencial de risco.

a) Vulnerabilidade do aquífero;

b) Cadastro das fontes potenciais de contaminação;

c) Zoneamento do uso e ocupaçáo do solo. 
Diante das informaçóes básicas, as dimensóes da malha de trabalho foram definidas de acordo com o tamanho que o mapa será apresentado. Posteriormente os dados são integrados para a obtenção do potencial de risco à contaminação de cada quadrante.

\section{CONCLUSÓES}

A urbanização da zona norte da cidade de Natal ocorreu de forma acelerada entre os anos de 1978 e 2006. A estrutura urbana da cidade não foi devidamente dimensionada em termos de obras estruturais como: abastecimento de água, saneamento e drenagem, capazes de suprir o correspondente aumento de demanda. Em consequência da falta de estrutura, foram gerados impactos sobre as águas subterrâneas notadamente pela disposição local de efluentes domésticos.

$\mathrm{Na}$ avaliação da vulnerabilidade pela aplicação do método (GOD) foi verificado que a 46\% da área de estudo apresenta uma vulnerabilidade média quanto a contaminação das águas subterrâneas. Os setores menos vulneráveis são da ordem de $21,6 \%$ e os mais vulneráveis compreendem apenas $9,26 \%$ da superfície total da área.

As áreas com baixo risco de contaminação correspondem às áreas topograficamente mais elevadas e os de risco mais elevados são verificados nos domínios de relevo mais baixo ou nas margens dos rios que drenam a periferia da área.

O processo de integração de dados de uso do solo associado ao mapa vulnerabilidade do aquífero através do método GOD mostra-se um mecanismo que se tem uma resposta positiva para contribuir com o conhecimento dos recursos hídricos subterrâneos na área de estudo.

\section{AGRADECIMENTOS}

Os autores agradecem o Instituto de Defesa do Meio Ambiente do Estado do Rio Grande do Norte (IDEMA) por fornecer as imagens de satélite da Zona Norte de Natal. Ao CNPq, UFRN (Departamento de Geologia), CAPES e UFPE (Programa de Pós-Graduação em Geociências) pelo apoio ao desenvolvimento deste trabalho.

\section{REFERÊNCIAS}

AGÊNCIA NACIONAL DE ÁGUAS - ANA. Estudos hidrogeológicos para a orientação do manejo das águas subterrâneas da região metropolitana de natal: avaliação da urbanização e de outras atividades antrópicas nas águas subterrâneas. Brasília, 2012. (v. 2). Disponível em: <http://metadados.ana.gov.br/geonetwork/srv/en/resources. get?id=424\&fname=RMN_RF_Volume_02-Avaliacao_da_Urbanizacao. pdf\&access=private>. Acesso em: 11 nov. 2016.

ARAÚJO, L. P. Sistema de informação geográfica aplicado à análise das relações da qualidade da água e risco em saúde pública no município de Natal (RN). 2002. Dissertação (Mestrado) - Depto de Geologia, CCET, UFRN, 2002.

CASTRO, C. M.; PEIXOTO, M. N. O.; RIO, G. A. P. Riscos ambientais e geografia: conceituações, abordagens e escalas. Anuário do Instituto de Geociências, Rio de Janeiro, v. 28, n. 2, p. 11-30, 2005. Disponível em: <http://www.anuario.igeo.ufrj.br/anuario_2005/Anuario_2005_11_30. pdf>. Acesso em: 8 nov. 2016.

COSTA, W. D. Estudo hidrogeológico de Natal/RN. Natal: Consultoria Técnica de Geologia e Engenharia (CONTEGE), Companhia de Águas e Esgotos do Rio Grande do Norte (CAERN), 1970.

FOSTER, S. S. D.; HIRATA, R. C. A. Groundwater pollution risk assessment: a methodology using available data. Lima: WHO-PAHO/ HPE-CEPIS Technical Manual, 1988.

FOSTER, S. S. D.; HIRATA, R. C. A. Determinação do risco de contaminação das águas subterrâneas: um método baseado em dados existentes. São Paulo: Instituto Geológico, 1993. 92 p. (Boletim, 10).

FOSTER, S. Fundamental concepts in aquifer vulnerability pollution risk and protection strategy. In: INTERNATIONAL CONFERENCE VULNERABILITY OF SOILAND GROUNDWATER TO POLLUTANTS, 1987, Noordwijk, The Netherlands. Proceedings... 1987.

FOSTER, S. et al. Protección de la calidad del agua subterráea: guia para empresas de agua, autoridades municipales y agencias ambientales. Banco Mundial, 2002. 115 p.

FOSTER, S. et al. Proteção da qualidade da água subterrânea: um guia para empresas de abastecimento de água, órgãos municipais e agências ambientais. Washington: World Bank Group, 2006. 114 p. Edição Brasileira Sevmar. Disponível em: <http://siteresources. worldbank.org/INTWRD/Resources/336486-1175813625542/ GroundwaterQualityProtectionGuide_Portugese.pdf>. Acesso em: 9 nov. 2016.

FUNCERN. Cadastramento e nivelamento de poços no aqüifero barreiras no município do Natal, RN. Secretaria de Recursos Hídricos do Rio Grande do Norte, CEFET-RN, IGARN, 2006a. (v. 1). Disponível em: <http:// www.igarn.rn.gov.br/conteudo/principal/Cadastro/Invent $\%$ C3\%A1rio\%20 dos $\% 20$ po\% C3\%A7os\%20Cadastrados.pdf>. Acesso em: 17 jan. 2008. 
FUNCERN. Cadastramento e nivelamento de poços no aqüifero barreiras no município do Natal, $R N$. Secretaria de Recursos Hídricos do Rio Grande do Norte, CEFET-RN, IGARN, 2006b. (v. 2). Disponível em: <http://www.igarn.rn.gov.br/conteudo/principal/Cadastro/ Relat\%C3\%B3rio\%20Final\%20do\%20Cadastro\%20Volume\%2001. pdf>. Acesso em: 17 jan. 2008.

GARCIA, C.; CONCEIÇÃO, F. T.; PEIXOTO, A. S. P. Vulnerabilidade intrínseca dos aquíferos no município de Piracicaba, através do método GOD. Revista Águas Subterrâneas, São Paulo, v. 32, n. 2, 2018. Disponivel em: <https://aguassubterraneas.abas.org/asubterraneas/ article/view/29141/18865>. Acesso em: 9 nov. 2016.

LOPES, A. R.; SCHEIBE, L. Vulnerabilidade e risco de contaminação das águas do Sistema Aquífero Serra Geral na Bacia do Rio do Peixe/ SC. Revista Brasileira de Recursos Hidricos, Porto Alegre, v. 20, n. 3, p. 560-570, 2015. http://dx.doi.org/10.21168/rbrh.v20n3.p560-570.

MELO, J. G. Avaliação dos riscos de contaminação e proteção das águas subterrâneas: zona norte de Natal, RN. Natal: Divisão de Hidrogeologia, Companhia de Águas e Esgotos do Rio Grande do Norte, 1998. Relatório interno.

MELO, J. G. et al. Avaliação das condições hidroambientais e definição de estratégias de manejo dos recursos hídricos nos domínios urbanose periurbanos da zona norte de Natal/RN. MCT/CNPq/CT-Hidro/CTAgro, 2009. Relatório final de pesquisa.

MELO, J. G. et al. Atualização de conhecimentos sobre a hidrogeologia e contaminação das águas subterrâneas da zona norte de Natal, RN. In: CONGRESSO BRASILEIRO DE ÁGUAS SUBTERRÂNEAS, 16., 2010 Anais... 2010.

MELO, J. G. et al. Avaliação hidrogeológica da Zona Norte da cidade de Natal, RN, e os problemas associados ao desenvolvimento urbano. Revista Brasileira de Recursos Hidricos, Porto Alegre, v. 17, p. 123-134, 2012.

MELO, J. G.; FIGUEREDO, E. M. Comportamento hidráulico e vulnerabilidade do sistema aquifero dunas/barreiras a poluição área de Natal/Rn. Revista Águas Subterrâneas, São Paulo, v. 13, p. 112124, 1990.

MELO, J. G.; REBOUCAS, A. C. Contaminação de águas subterrâneas por nitrato na zona sul de Natal, RN. Revista Águas Subterrâneas, São Paulo, v. 1, p. 71-83, 1996.
MELO, J. G.; VASCONCELOS, M. B.; ALVES, R. S. Problemas de manejo de águas subterrâneas em ambientes urbanos: o caso do município de Natal, RN. In: SIMPÓSIO BRASILEIRO DE RECURSOS HÍDRICOS, 12., 2011, Maceió. Anais... Porto Alegre: ABRH, 2011.

MIGLIORINI, R. B. Hidrogeologia em meio urbano: região de Cuiabá e Várzea Grande/MT. Tese (Doutorado) - USP, 2000.

RAUBER, A. C. et al. Aplicação dos métodos GOD e POSH para determinação da vulnerabilidade e perigo a contaminação dos aquíferos de Santa Maria-RS. REGA. Revista de Gestão de Águas da América Latina, Porto Alegre, v. 12, p. 61-79, 2015. Disponível em: <http://www.abrh.org. br/SGCv3/UserFiles/ Sumarios/19a7f83aa5a7499a23ca0433b7750f5c 354b4bdec8e1107a770afca63c33e898.pdf>. Acesso em: 8 nov. 2016.

RIGHETTO, A. M.; ROCHA, M. A. Exploração Sustentada do Aquífero Dunas / Barreiras na cidade de Natal, RN. Revista Brasileira de Recursos Hidricos, Porto Alegre, v. 10, n. 2, p. 27-38, 2005. http:// dx.doi.org/10.21168/rbrh.v10n2.p27-38.

VASCONCELOS, M. B. Análise integrada dos efeitos da expansão urbana nas águas subterrâneas como suporte a gestão dos recursos hidricos da zona norte de Natal - RN. 2010. 150 f. Tese (Doutorado) - Programa de Pós-graduação em Geociências, UFPE, Recife, 2010.

VASCONCELOS, M. B.; MELO, J. G.; DEMÉTRIO, J. G. A. Configuração hidrogeológica do sistema aquífero Dunas/Barreiras na zona norte de Natal, Rio Grande do Norte, Brasil. Boletim do Museu Paraense Emílio Goeldi: Ciências Naturais, Belém, v. 10, n. 1, p. 145, 2015. Disponível em: <http://www.museu-goeldi.br/editora/bn/artigos/cnv10n1_2015/ configuracao(vasconcelos).pdf>. Acesso em: 11 nov. 2016.

VOIGT, H. J. et al. Characterization of groundwater vulnerability in aquifer vulnerability and risc. In: INTERNATIONAL WORKSHOP ON AQUIFER VULNERABILITY AND RISK, 1., 2003, Salamanca Guanajuato, Mexico. Proceedings... 2003. p. 266-277.

VRBA, J. Groundwater vulnerability assessment and mapping. In: ZEKTSER, I. S.; EVERETT, L. G. (Orgs.). Groundwater resources of the world and their use. UNESCO, 2004. cap. 4.4, p. 97-104. (IHP-VI, Series on Groundwater, 6).

VRBA, J.; ZAPOROZEC, A. Guidebook on mapping groundwater vulnerability. Hannover: $\mathrm{H}$. Heise, 1994. 131 p. (IAH International Contributions to Hydrogeology, 16). 
Contribuição do autor:

Prof. do Dep. de Geologia da

Pesquisa realizada como parte de estudo da tese de doutorado do autor. Elaboração e formatação geral, confecção de mapas, discussão dos resultados das análises e revisão do manuscrito.

\section{José Geraldo de Melo}

Rio Grande do Norte-UFRN Programa de Pós-Graduação em Geodinâmica e Geofísica da UFRN-PPGG. jgmelo2@gmail.com

Contribuição do autor:

Discussão dos resultados das análises e revisão do manuscrito.

José Geilson Alves Demetrio

Prof. do Dep. de

Geologia da Universidade Federal de Pernambuco-UFPE Programa de Pós-graduação em Geociências da UFPE. geilson@ufpe.br

Contribuição do autor:

Discussão dos resultados das análises e revisão do manuscrito.

Rafaela da Silva Alves

Universidade Federal do Rio Grande do Norte-UFRN

Programa de Pós-Graduação em Geodinâmica e Geofísica-PPGG. alves. rafaelasilva@gmail.com

Contribuição do autor:

Discussão dos resultados das análises e revisão do manuscrito. 